\title{
Dietary Fat Clearance in Normal Subjects Is Regulated by Genetic Variation in Apolipoprotein E
}

\author{
Moshe S. Weintraub, Shlomo Eisenberg, ${ }^{\star}$ and Jan L. Breslow \\ Laboratory of Biochemical Genetics and Metabolism, The Rockefeller University, New York, New York 10021; *Department of \\ Medicine B, Hadassah University Hospital, Jerusalem, Israel
}

\begin{abstract}
Apolipoprotein E (apo E) plays an important role in receptor mediated clearance of lipoprotein particles from plasma. Common genetic variation in apo $\mathbf{E}$ exists with three alleles coding for proteins called E2, E3, and E4. In in vitro receptor binding assays, E2 binds poorly, whereas E3 and E4 function normally. Recently, the apo $\mathbf{E}$ phenotype has been shown to have an effect on low density lipoprotein (LDL) cholesterol levels with levels in subjects with E2 lower and E4 higher than E3. We have examined the effect of the apo $E$ polymorphism on dietary fat clearance using the vitamin A-fat loading test, which specifically labels intestinally derived lipoproteins with retinyl palmitate (RP). 27 normal subjects were studied, 10 with E3/3, 9 with $E 3 / 2,7$ with $E 4 / 3$, and 1 with $E 4 / 4$. After a vitamin A-containing fatty meal, postprandial RP concentrations were measured in chylomicron $\left(S_{\mathrm{f}}>1,000\right)$ and nonchylomicron $\left(S_{\mathrm{f}}\right.$ $<1,000)$ fractions for $14 \mathrm{~h}$. Compared with E3/3 subjects, E3/2 subjects had a significantly higher nonchylomicron RP concentration $(P<0.05)$ (peak heights and areas below the curves) indicating slower clearance and the E4/3, E4/4 group had a significantly lower nonchylomicron RP concentration ( $P$ $<0.05$ ) indicating faster clearance. The clearance in the latter group was twice that of $E 3 / 2$ subjects $(P<0.01)$. Thus, heterozygosity for the defective form of apo E, E2, delays, and the surprising presence of a functionally normal allele, E4, increases clearance. This apo $E$ effect on exogenous fat clearance may explain the recently described effect of the apo $\mathbf{E}$ phenotypes on LDL cholesterol levels.
\end{abstract}

\section{Introduction}

Apolipoprotein (apo) $\mathrm{E}$ is a constituent of plasma very low density lipoproteins (VLDL), intermediate density lipoproteins (IDL), high density lipoproteins (HDL), and chylomicron remnants (1-3). It is recognized by LDL receptors and hepatic chylomicron remnant receptors and mediates hepatic uptake of IDL and chylomicron remnants, and in this manner, plays an important role in lipoprotein metabolism (4-8). Different forms of apo $E$ have been recognized in humans due to genetic variation in the apo $E$ gene resulting from three common alleles in the population, $\epsilon 4, \epsilon 3$ and $\epsilon 2$, with frequencies

Address reprint requests to Dr. Breslow, The Rockefeller University, 1230 York Avenue, New York, NY 10021.

Received for publication 27 February 1987 and in revised form 9 July 1987.

J. Clin. Invest.

(C) The American Society for Clinical Investigation, Inc.

$0021-9738 / 87 / 12 / 1571 / 07 \quad \$ 2.00$

Volume 80, December 1987, 1571-1577 of $\sim 15,75$, and $10 \%$, respectively. These alleles produce gene products with different isoelectric points, designated from basic to acidic, E4, E3, and E2, respectively. These three alleles result in three homozygous phenotypes, E4/4, E3/3, and E2/2, with approximate frequencies 2,56 , and $1 \%$, respectively, and three heterozygous phenotypes, E4/3, E3/2, and E4/2, with approximate frequencies 23,15 , and $3 \%$, respectively $(9-16)$.

Type III hyperlipoproteinemia, a disorder characterized by increased cholesterol and triglyceride levels (due to the presence of chylomicron remnants in fasting plasma), premature coronary and peripheral vascular disease, and tuberoeruptive and palmar xanthomas is strongly associated with the E2/2 phenotype present in $1 \%$ of the population $(10,17,18)$. E2 binds poorly to receptors and this is thought to account for the defective chylomicron remnant clearance in this disorder (19, 20). The influence of the other apo $E$ phenotypes on dietary fat clearance has not been studied.

Recently, population based studies have shown that the apo $E$ polymorphism is associated with differences in plasma LDL levels. Phenotypes E4/4 and E4/3 are associated with higher and E3/2 and E2/2 with lower LDL cholesterol levels than E3/3 (12, 13, 21-24). The association of elevated LDL cholesterol levels with coronary heart disease susceptibility is well documented $(25,26)$ and heightens the importance of understanding the influence of the apo $\mathrm{E}$ phenotype on LDL levels. Apo $E$ is not a constituent of LDL and its influence must be indirect.

In the current study, we used the vitamin A-fat loading test, which specifically labels intestinally derived lipoproteins with retinyl palmitate (27-34), to follow the metabolism of exogenous fat to see if the apo $E$ phenotype affects dietary fat clearance. We show that the common apo E phenotypes do affect dietary fat clearance and we then present a model whereby this may explain the effect of the apo E phenotype on LDL cholesterol levels.

\section{Methods}

Subjects. 27 normolipidemic, healthy volunteers participated in the study. None of them had diabetes or liver, renal, or thyroid disease. At the time of the vitamin A-fat loading test, 16 subjects were inpatients on the Rockefeller University Hospital Metabolic Ward. They were stabilized for $3 \mathrm{wk}$ on a metabolic diet containing $42 \%$ of calories from fat (caloric distribution: fat $42 \%$, protein $15 \%$, carbohydrate $43 \%$, with a polyunsaturated/saturated $(\mathrm{P} / \mathrm{S})$ ratio of 0.1 and a cholesterol intake of $175 \mathrm{mg} / 1,000 \mathrm{cal})$. The other 11 subjects were admitted to the hospital the morning of the study and remained hospitalized for $24 \mathrm{~h}$. By diet history, these subjects were not on any dietary restrictions. Apo $E$ phenotypes of the 16 inpatient subjects were $E 3 / 2=5, E 3 / 3=7$ and $\mathrm{Er} / 3,4 / 4=4$. Apo $E$ phenotypes of the 11 outpatient subjects were $\mathrm{E} 3 / 2=3, \mathrm{E} 3 / 3=4$, and $\mathrm{E} 4 / 3=4$.

Vitamin A-fat loading test. The vitamin A-fat loading test was performed as recently described (34). After an overnight 12 -h fast, 
subjects were given a fatty meal plus $60,000 \mathrm{U}$ of aqueous vitamin $\mathrm{A} / \mathrm{m}^{2}$ body surface. The fatty meal contained $50 \mathrm{~g}$ of fat $/ \mathrm{m}^{2}$ body surface, consisting of $65 \%$ of calories as fat, $20 \%$ as carbohydrate, and $15 \%$ as protein. It contained $600 \mathrm{mg}$ cholesterol/1,000 calories, and the $\mathrm{P} / \mathrm{S}$ ratio was 0.3 . This was given as a milkshake, scrambled eggs, bread and cheese, and was eaten in $10 \mathrm{~min}$. The vitamin $A$ was added to the milkshake. After the meal, subjects stayed fasting for $14 \mathrm{~h}$, but as much drinking water was allowed as desired. To measure levels of retinyl palmitate, blood samples were drawn before the meal and every hour after the meal until $6 \mathrm{~h}$, then every $2 \mathrm{~h}$ until $14 \mathrm{~h}$. The subjects tolerated the meal well, and no one had diarrhea or other symptoms of malabsorption.

Analysis of samples. Venous blood was drawn from the forearm and transferred to a tube containing sodium EDTA. Samples were immediately centrifuged at $1,500 \mathrm{~g}$ for $15 \mathrm{~min}$ and $0.5 \mathrm{ml}$ of plasma was stored wrapped in foil at $-20^{\circ} \mathrm{C}$ for retinyl ester assay. Another 0.5 $\mathrm{ml}$ was stored at $4^{\circ} \mathrm{C}$ for triglyceride determinations. An aliquot of 2.5 $\mathrm{ml}$ of plasma was transferred into a $1 / 2 \times 2$ in. cellulose nitrate tube and overlayered with $2.5 \mathrm{ml}$ sodium chloride solution $(d=1.006 \mathrm{~g} / \mathrm{ml})$. Tubes were subjected to preparative ultracentrifugation for $1.6 \times 10^{6}$ $g$-min in a rotor (SW-55; Beckman Instruments, Inc., Fullerton, CA) to float chylomicron particles of $S_{\mathrm{f}}>1,000$ (35-37). The chylomicroncontaining supernatant was removed and brought to a total volume of $2 \mathrm{ml}$ with saline. The infranatant was brought to a volume of $5 \mathrm{ml}$ with saline. $0.5-\mathrm{ml}$ aliquots of supernatant and infranatant were wrapped in foil and assayed for retinyl ester. Additional aliquots were assayed for triglyceride concentration. As discussed elsewhere, the procedure appears to separate a predominantly chylomicron population from a predominantly remnant population $(34,35)$.

Retinyl ester assay. The assays were carried out in subdued light with HPLC grade solvents. Retinyl acetate was added to the samples as an internal standard. The samples were then mixed with ethanol $4 \mathrm{ml}$, hexane $5 \mathrm{ml}$, and water $4 \mathrm{ml}$ with vortexing between each addition. Two phases were formed and $4 \mathrm{ml}$ of the upper (hexane) phase was removed and evaporated under nitrogen (38). The residue was dissolved in a small volume of benzene, and an aliquot was injected into an HPLC $5 \mu \mathrm{m}$ ODS-18 radial compression column. $100 \%$ methanol was used as the mobile phase at a flow rate of $2 \mathrm{ml} / \mathrm{min}$. The effluent was monitored at $340 \mathrm{~nm}$, and the peak of retinyl palmitate $(R P)^{1}$ was identified by comparison to the retention time of purified standard (Sigma Chemical Co., St. Louis, MO). In agreement with previous reports $(31,33)$, it was found that $75-80 \%$ of total plasma retinyl esters were accounted for by retinyl palmitate. In addition, the distribution of retinyl esters remained constant throughout the study. The amounts of $\mathrm{RP}$ in plasma and lipoprotein fractions were quantitated by the area ratio method (39) using retinyl acetate as a reference (34).

Lipid and lipoprotein determination. Cholesterol and triglycerides were measured enzymatically using the reagents cholesterol 236691 and triglyceride 126012 (Boehringer Mannheim, Inc., Indianapolis, IN). Total and HDL cholesterol measurements were standardized by the Lipid Standardization Program of the Center for Disease Control, Atlanta, Georgia. HDL cholesterol was determined after precipitation of whole plasma with dextran sulfate-magnesium (40). HDL plus LDL cholesterol was measured on the infranatant after a 2-h spin in the Beckman airfuge to float the VLDL. Appropriate corrections were made for dilution factors, and VLDL, LDL, and HDL cholesterol levels were calculated.

Apolipoprotein E phenotyping. $5 \mathrm{ml}$ of plasma was added to each of two quick-seal ultracentrifuge tubes, $1 / 2 \times 2 \frac{1}{2}$ in. The tubes were filled to the top with saline, sealed, and spun at $39,000 \mathrm{rpm}$ for $20 \mathrm{~h}$ at $4^{\circ} \mathrm{C}$ using a 40.3 Beckman rotor. The floating VLDL layer was removed with a syringe and transferred to a glass tube for delipidation with ethanol/acetone $1: 1$ at a temperature of $-20^{\circ} \mathrm{C}$. The tubes were vortexed, kept at $-20^{\circ} \mathrm{C}$ for $1 \mathrm{~h}$, spun, and the supernatant discarded. The

1. Abbreviations used in this paper: HTGL, hepatic triglyceride lipase; LPL, lipoprotein lipase; RP, retinyl palmitate. pellet was washed twice with cold ether, and dissolved in 0.2 to $0.3 \mathrm{ml}$ of a buffer containing $6 \mathrm{M}$ urea, $0.01 \mathrm{M}$ Tris $\mathrm{HCl}, 0.01 \mathrm{M}$ dithiothreitol, pH 8.6. Protein concentration was determined by a Bio-Rad assay using bovine serum albumin as a reference. A one-dimensional isoelectric focusing gel was prepared in a 6-M urea buffer containing $7.5 \%$ acrylamide, $0.2 \% N, N^{\prime}$-methylene-bis-acrylamide (BIS) and $2 \%$ ampholines of $\mathrm{pH} 4-6.5$. The gel was prefocused for $1 \mathrm{~h}$ at $4^{\circ} \mathrm{C}$ at $110 \mathrm{~V}$, and then $50 \mu \mathrm{g}$ of VLDL protein was applied to each gel lane. Focusing was carried out for $17 \mathrm{~h}$ at $4^{\circ} \mathrm{C}$ at $250 \mathrm{~V}$. After focusing, the gels were fixed in trichloroacetic acid-sulfosalicylic acid, stained with Coomassie Blue $(0.1 \%)$ in methanol, water, acetic (4.5:4.5:1.0), and destained. Specimens from individuals with known apo $\mathrm{E}$ phenotypes were run along with new samples to aid in the interpretation of the results.

Postheparin plasma lipolytic activities. Lipolytic activities were determined 1 wk before the vitamin A-fat loading test. Lipoprotein lipase (LPL) and hepatic triglyceride lipase (HTGL) were released into the circulation by intravenous heparin injection at a dose of $60 \mathrm{U} / \mathrm{kg}$ body wt. After 15 min blood was drawn into tubes containing 4 mM EDTA. The plasma was immediately separated at $4^{\circ} \mathrm{C}$ by centrifugation at $2,700 \mathrm{rpm}$ for $12 \mathrm{~min}$ and promptly frozen at $-70^{\circ} \mathrm{C}$. The assay itself is a modification of the method of Krauss (41) as recently described (34). In short, $20 \mu \mathrm{l}$ of postheparin plasma is added to freshly sonified substrate, containing radiolabeled and unlabeled triolein and triton in a Tris $\mathrm{HCl}$ buffer $\mathrm{pH} 8.6$, mixed, and incubated for $20 \mathrm{~min}$ at $37^{\circ} \mathrm{C}$. The reaction is stopped by a mixture of chloroform, methanol, and heptane, and a base in the form of $\mathrm{K}_{2} \mathrm{CO}_{3}$ is added. After mixing and centrifugation, an aliquot of the aqueous phase is counted and the total lipolytic activity is given as micromoles FFA liberated/milliliter plasma/hour. Another aliquot of $20 \mu \mathrm{l}$ of postheparin plasma is incubated for $1 \mathrm{~h}$ at $4^{\circ} \mathrm{C}$ with $25 \mu \mathrm{l}$ of rabbit anti-human LPL antiserum before the lipase assay described above. The antiserum was prepared in our laboratory by injecting rabbits with LPL purified from fresh human breast milk. This antiserum completely inhibited the activity of purified human breast milk lipoprotein lipase, but had no effect on human hepatic lipase purified by heparin Sepharose chromatography from postheparin plasma. LPL activity is the difference between total and antiserum-inhibited activity. The latter is taken to be the HTGL activity.

Statistical analysis. The differences between groups of subjects were analyzed for significance mainly using unpaired Student $t$ tests. Differences in dietary fat clearance between the apo $E$ phenotype groups were also sought using analysis of variance, and Duncan's multiple comparison tests. Calculations were performed on The Rockefeller University Hospital CLINFO system.

\section{Results}

Subject characteristics. The clinical features, lipid levels, and plasma postheparin lipolytic activities for groups of subjects are presented in Table I. When males and females are compared, males had lower HDL cholesterol levels $(P=0.003)$ and a trend towards lower LPL and higher HTGL activities, $P$ $=0.11$ and $P=0.054$, respectively. The subjects were also grouped by age as older (40-72 yr) and younger (19-28 yr). Older subjects had lower LPL $(P=0.019)$ and higher HTGL $(P=0.032)$ activities when compared with younger subjects. Apo E phenotype analysis revealed 9 subjects with E3/2, 10 with E3/3, 7 with E4/3, and 1 with E4/4. There were no subjects with $E 4 / 2$ or E2/2. For purposes of analysis, the results from the person with E4/4 were combined with those for the E4/3 group. This did not substantially affect any of the results. E3/2 individuals had lower LDL cholesterol levels than E3/3 subjects $(P=0.003)$, whereas those in the $\mathrm{E} 4 / 3, \mathrm{E} 4 / 4$ grouping showed a trend to higher LDL cholesterol levels than E3/3 individuals, but this was not significant $(P=0.116)$. The apo $\mathrm{E}$ 


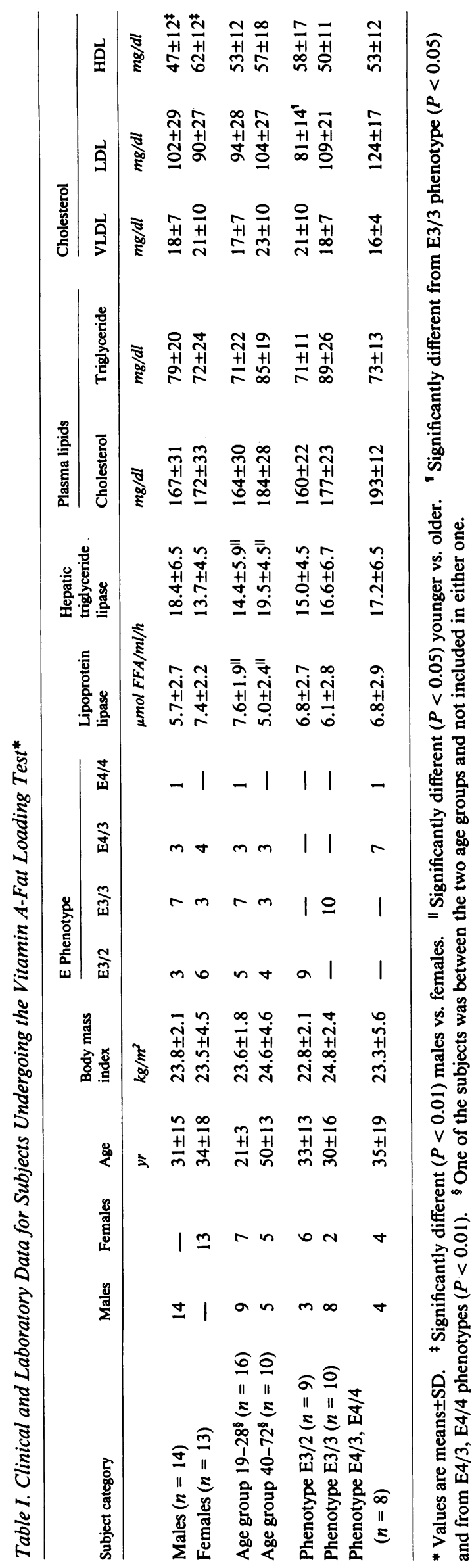

phenotype groupings did not differ with respect to other parameters such as postheparin lipase activities.

Effects of age and sex on dietary fat clearance. Plasma chylomicron and nonchylomicron RP concentrations during the vitamin A-fat loading test for the different groups are shown in Fig. 1. Table II represents the means and SD of the peak RP response and area below the curves. There was no significant effect of sex, but males showed a tendency to a higher chylomicron RP response. Age affected chylomicron RP response with older subjects having $33 \%$ higher RP peak values and 50\% higher RP area $(P<0.05)$. There was no effect of age on the magnitude of the nonchylomicron RP response. The peak level of chylomicron and nonchylomicron RP was slightly delayed in older subjects. From the shape of the curves, this was possibly due to diminished chylomicron RP clearance, which is compatible with the lower LPL activity measured in older subjects.

Effects of the apo E phenotype on dietary fat clearance. The chylomicron and nonchylomicron RP response to the vitamin A-fat loading test in subjects with different apo $E$ phenotypes are shown in Fig. 1 and Table II. In contrast to the age effects, the apo E phenotype had no effect on the chylomicron RP response, but had a significant effect on the nonchylomicron fraction. In both peak height and area below the curve, the nonchylomicron RP fraction was highest in E3/2 subjects, intermediate in E3/3 subjects, and lowest in the E4/3, E4/4 group. The values for $E 3 / 3$ subjects were significantly different from each of the other two groups $(P<0.05)$. The $\mathrm{E} 3 / 2$ values were over twofold greater than the E4/3, E4/4 subjects $(P$ $<0.01)$. Analysis of variance also showed that the three apo $\mathrm{E}$ phenotype groups differed significantly $(P=0.0015)$. Duncan's multiple comparison test revealed significant differences between any two of the groups $(P<0.05)$.

Fig. 2 presents the data for total plasma, chylomicron, and nonchylomicron RP peak heights during the vitamin A-fat loading test in individual subjects. For the nonchylomicron $R P$ response, a comparison of subjects with the $E 3 / 2$ and $E 4 / 3$, E4/4 phenotypes shows almost no overlap. Furthermore, none of the E4/3, E4/4 subjects had a response higher than the mean for the E3/3 group, and only one subject with E3/2 had a response lower than the E3/3 mean.

During the vitamin A-fat loading test total plasma, chylomicron, and nonchylomicron triglyceride responses were analyzed (data not shown). Older subjects showed a significantly higher chylomicron triglyceride response $(P<0.05)$. However, there were no differences in the nonchylomicron responses between the apo E phenotypes, as seen in the vitamin A-fat loading test. This reflects the fact that triglyceride levels are not a sensitive or specific way to determine nonchylomicron response to a fatty meal, because of the presence of a large pool of triglyceride-rich lipoproteins of endogenous origin in the $S_{\mathrm{f}}$ $<1,000$ plasma fraction (34).

To assess whether diet might affect the results observed, the 16 subjects studied as inpatients on the $42 \%$ fat diet were restudied with the same fatty meal after $3 \mathrm{wk}$ on an American Heart Association Phase II diet (caloric distribution: fat 25\%, protein $15 \%$, carbohydrate $60 \%$, with a P/S ratio of 1.3 and a cholesterol intake of $85 \mathrm{mg} / 1,000 \mathrm{cal}$ ). For individual subjects, no differences were found between the diets (data not shown). Thus age, sex, and diet variables could not confound the observation of an apo $E$ phenotype effect on the clearance of the nonchylomicron fraction. 


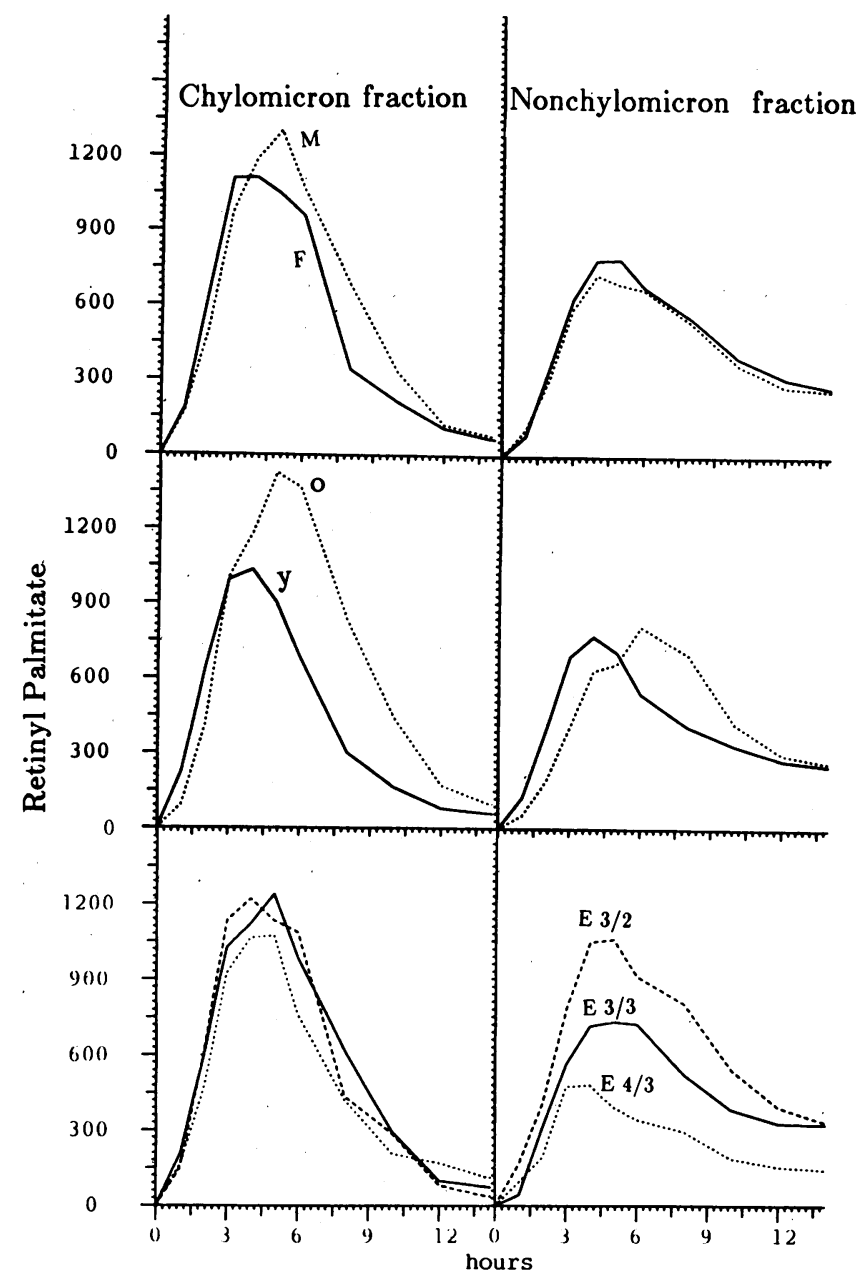

Figure 1. Effect of sex, age, and apolipoprotein E polymorphism on chylomicron and nonchylomicron RP concentration curves (in micrograms per liter) in normal subjects. The upper panel shows RP responses of males $(\cdots)(n=14)$ and females $(=)(n=13)$. The middle panel compares older $(\cdots \cdots)(n=10)$ to younger $(-)(n$ $=16)$ subjects. The lower panel shows RP responses of subjects with apo E3/2 (- $)(n=9)$, apo E3/3 $(-)(n=10)$, and apo E4/3, $\mathrm{E} 4 / 4(\cdots)(n=8)$ phenotypes. For each group, the levels at each time point were averaged.

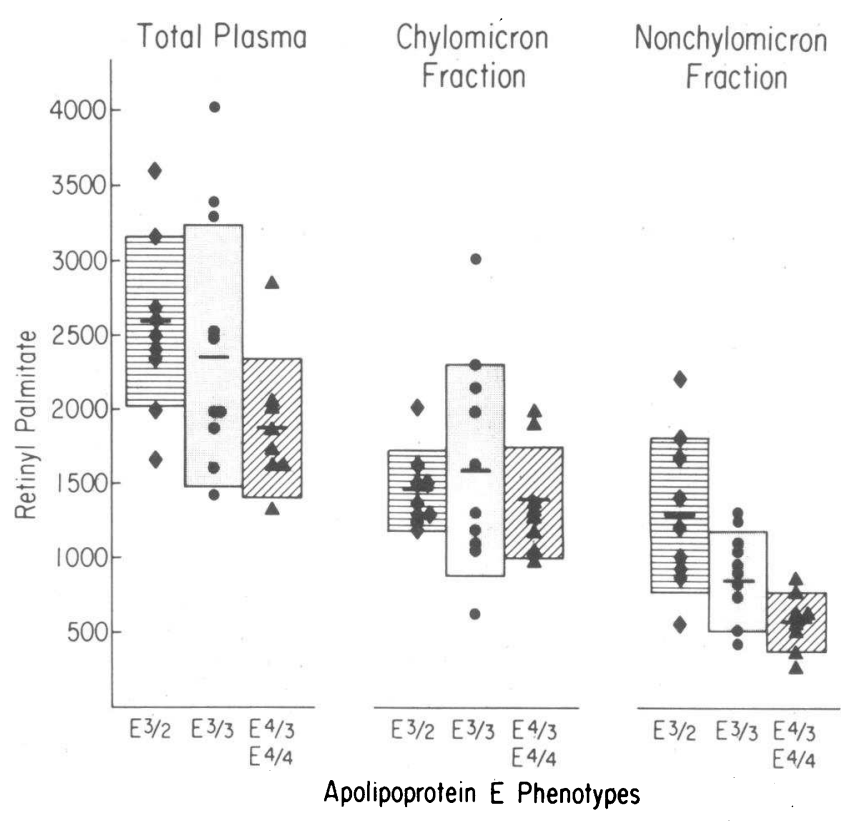

Figure 2. RP peak heights (in micrograms per liter) of total plasma, chylomicron, and nonchylomicron fractions during the vitamin A-fat loading test in individual subjects with different apo $E$ phenotypes.

\section{Discussion}

The aim of the present investigation was to determine the effect of the common apo $E$ protein polymorphism on the metabolism of dietary fats. The basis for this polymorphism is variation in the apo $\mathrm{E}$ gene (9-11). The most common allele gene product, E3, is a 299 amino acid polypeptide (42), whose receptor binding region resides between residues 140 and 160 (43-45). E3 contains a single cysteine at residue 112. The two common polymorphic forms of apo E differ from E3 at a single amino acid residue. E2 contains a cysteine for arginine substitution at residue 158 and has $<1 \%$ of normal receptor binding capacity in in vitro assays $(19,20)$. E4 contains an arginine for cysteine substitution at residue 112 and has normal in vitro receptor binding capacity (19).

Table II. Effect of Sex, Age, and Apo E Phenotype on Total Plasma, Chylomicron, and Nonchylomicron RP Responses*

\begin{tabular}{|c|c|c|c|c|c|c|}
\hline \multirow[b]{2}{*}{ Subject category } & \multicolumn{3}{|l|}{ RP peak levels } & \multicolumn{3}{|l|}{ Area below RP curves } \\
\hline & Total plasma & $\begin{array}{l}\text { Chylomicron } \\
\text { fraction }\end{array}$ & $\begin{array}{l}\text { Nonchylomicron } \\
\text { fraction }\end{array}$ & Total plasma & $\begin{array}{l}\text { Chylomicron } \\
\text { fraction }\end{array}$ & $\begin{array}{l}\text { Nonchylomicron } \\
\text { fraction }\end{array}$ \\
\hline & $\mu g /$ liter & $\mu g /$ liter & $\mu g /$ liter & $\mu g / l i t e r / h$ & $\mu g / l i t e r / h$ & $\mu g / l i t e r / h$ \\
\hline Males $(n=14)$ & $2,482 \pm 749$ & $1,626 \pm 578$ & $856 \pm 276$ & $14,767 \pm 4,465$ & $8,672 \pm 3,638$ & $6,095 \pm 2,107$ \\
\hline Females $(n=13)$ & $2,365 \pm 712$ & $1,397 \pm 335$ & $968 \pm 603$ & $13,398 \pm 4,642$ & $6,856 \pm 2,128$ & $6,542 \pm 3,331$ \\
\hline Age group $19-28(n=16)$ & $2,110 \pm 514$ & $1,234 \pm 223$ & $876 \pm 386$ & $12,928 \pm 4,000$ & $6,062 \pm 2,077^{\ddagger}$ & $6,866 \pm 2,382$ \\
\hline Age group $40-72(n=10)$ & $2,620 \pm 864$ & $1,652 \pm 402$ & $968 \pm 611$ & $15,365 \pm 5,066$ & $9,073 \pm 2,097^{\ddagger}$ & $6,292 \pm 3,353$ \\
\hline Phenotype E3/2 $(n=9)$ & $2,740 \pm 571^{8}$ & $1,450 \pm 265$ & $1,290 \pm 502^{\|, 1}$ & $15,947 \pm 3,630^{11}$ & $7,507 \pm 2,148$ & $8,454 \pm 2,120^{\|, 1}$ \\
\hline Phenotype E3/3 $(n=10)$ & $2,537 \pm 872$ & $1,609 \pm 759$ & $928 \pm 252$ & $14,914 \pm 3,017$ & $8,653 \pm 2,451$ & $6,260 \pm 1,321$ \\
\hline $\begin{array}{l}\text { Phenotype E4/3, E4/4 } \\
\quad(n=8)\end{array}$ & $1,962 \pm 464^{8}$ & $1,388 \pm 369$ & $574 \pm 192^{\|,}$ & $10,556 \pm 2,095^{11,1}$ & $6,527 \pm 2,116$ & $4,029 \pm 1,561^{11,1}$ \\
\hline
\end{tabular}

* Values are means \pm SD. ${ }^{\ddagger}$ Significantly different $(P<0.05)$ younger vs. older. ${ }^{8}$ Significantly different $(P<0.05)$ E3/2 vs. E4/3, E4/4. " Significantly different $(P<0.01)$ E3/2 vs. E4/3, E4/4. ' 'Significantly different $(P<0.05)$ E3/2 vs. E3/3 and/or E4/3, E4/4 vs. E3/3. 
Subjects homozygous for the defective form of apo E, with the E2/2 phenotype, can develop an overt fasting hyperlipidemia, called type III hyperlipoproteinemia. This is characterized by the presence of chylomicron remnants in fasting plasma $(10,17,18)$. This is not surprising since chylomicron remnants depend on apo $\mathrm{E}$ for recognition and clearance by the liver chylomicron remnant receptor. Although the E2/2 phenotype is present in $1 \%$ of the population, $<5 \%$ of people with E2/2 have overt type III hyperlipoproteinemia and disease expression is related to age, diet, adiposity, hormonal status, and probably the presence of other hyperlipidemia genes $(46,47)$. Even in normolipidemic E2/2 subjects, elevated levels of chylomicron remnants have been described implying decreased clearance $(22,33,48)$.

We have previously shown that the vitamin A-fat loading test, as applied in our laboratory, is an adequate tool to follow the metabolism of large and small postprandial fat particles, which we believe correspond principally to chylomicron and chylomicron remnants, respectively. The large particles $\left(S_{\mathrm{f}}\right.$ $>1,000)$ called the chylomicron fraction in normal people are cleared in proportion to HDL levels and postheparin lipoprotein lipase activity. In addition, their clearance is delayed in type IV patients with improvement documented after gemfibrozil therapy. The small particles $\left(S_{\mathrm{f}}<1,000\right)$ called the nonchylomicron fraction in normal people are cleared in proportion to postheparin hepatic triglyceride lipase levels and show delayed clearance in type III hyperlipoproteinemic patients (34). In the current study, we show that individuals with the E3/2 phenotype have delayed postprandial clearance of the small particles, the nonchylomicron fraction that behaves like chylomicron remnants. This is similar, but in a milder form, to what is seen in E2/2 individuals and documents a metabolic defect in postprandial fat metabolism in carriers of the defective allele, E2, who comprise $\sim 15 \%$ of the general population.

A very surprising result of the current study was that individuals with the E4/3 phenotype, who comprise $\sim 23 \%$ of the general population, actually had accelerated postprandial clearance of the nonchylomicron fraction. This suggests that they clear chylomicron remnants into the liver more rapidly than E3/3 individuals and strikingly twice as fast as E3/2 individuals. E4 behaves normally in receptor binding assays (19) compatible with its amino acid substitution being outside of the receptor binding region. Therefore, another explanation is required to explain its anomalous behavior compared to E3. One hypothesis is the following (Fig. 3): In the fasting state it

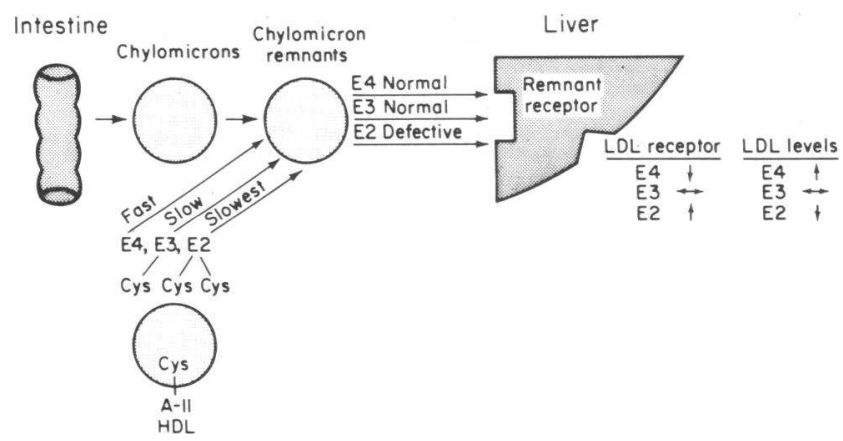

Figure 3. Schematic diagram of a possible mechanism by which the common apo $\mathrm{E}$ phenotypes affect chylomicron remnant uptake by liver and LDL cholesterol levels in plasma. has been observed that most plasma apo $\mathrm{E}$ resides in $\mathrm{HDL}$ and after fat ingestion apo E shifts from HDL to postprandial particles (49-51). Since E4 contains no cysteine, where E3 contains one residue of cysteine, it can be conjectured that E4 in HDL cannot form disulfide bonds with other proteins and shifts more rapidly than E3 to chylomicron remnants. Disulfide bonding of apo E to apo A-II in HDL has been demonstrated (52). In this manner individuals with E4 might more efficiently and rapidly deliver dietary fat to the liver. A recent study injecting radiolabeled E4 and E3 showed that E4 was cleared more rapidly than E3 from plasma and that E3 preferentially associated with HDL (53). These observations are compatible with the hypothesis.

Very recently, it has become apparent that the common apo E phenotypes profoundly affect LDL cholesterol levels in the general population. In comparison to $\mathrm{E} 3 / 3$ individuals (56\% of population), E3/2 individuals have lower and E4/3 individuals have higher LDL cholesterol levels (12, 13, 21-24). The LDL levels in the current study show the same trend and the difference seen between the phenotypes in the metabolic behavior of postprandial particles suggest a mechanism for the LDL observations (Fig. 3). The liver is the main site of removal of plasma LDL. It is a dynamic organ with several constantly active, regulated mechanisms affecting its cholesterol and fatty acid pools. Therefore, the rate of exogenous fat removal by the liver could influence the liver's rate of removal of endogenous fat containing particles. One mechanism could be by LDL receptor regulation. Thus, the slower hepatic clearance of dietary fat in E3/2 subjects could result in up regulation of LDL receptors, and a decrease in plasma LDL levels. The faster hepatic clearance of dietary fat in E4/3 subjects could cause the opposite, down regulation of LDL receptors, and an increase in plasma LDL levels. A recent analysis estimated that $16 \%$ of the genetic variation in LDL cholesterol levels in the general population could be accounted for by the three structural alleles at the apo E gene locus (54). The data presented in the current report could explain the mechanism of this relationship.

\section{Acknowledgments}

We thank Ms. Bahareh Sahami and Ms. Margaret Timmons for expert technical assistance, Dr. Rudolf Zechner for preparation of the antibody to lipoprotein lipase, Mr. Thomas Reingold for help with data analysis, and Ms. Lorraine Duda for help in preparation of the manuscript.

Supported in part by grants from the National Institutes of Health (HL-32435, HL-33714, AG-04727, CA-29502) and a General Clinical Research Center grant (RR-00102), as well as general support from the Pew Trusts. Dr. Breslow is an Established Investigator of the American Heart Association.

\section{References}

1. Shore, B., and V. G. Shore. 1973. Heterogeneity of human plasma very low density lipoproteins. Separation of species differing in protein components. Biochemistry. 12:502-507.

2. Blum, C., L. Aron, and R. Sciacca. 1980. Radioimmunoassay studies of human apolipoprotein E. J. Clin. Invest. 66:1-40.

3. Havel, R. J., L. Kotite, J. L. Vigne, J. P. Kane, P. Tun, N. Phillips, and G. C. Chen. 1980. Radioimmunoassay of human arginine-rich apolipoprotein, apoprotein E. J. Clin. Invest. 66:1351-1362.

4. Sherill, B. C., T. L. Innerarity, and R. W. Mahley. 1980. Rapid 
hepatic clearance of canine lipoproteins containing only the $\mathrm{E}$ apoprotein by high affinity receptor (identity with the chylomicron remnant transport process). J. Biol. Chem. 255:1804-1807.

5. Windler, E., Y. Chao, and R. J. Havel. 1980. Regulation of the hepatic uptake of triglyceride-rich lipoproteins in the rat: opposing effects of homologous apolipoprotein $\mathrm{E}$ and individual $\mathrm{C}$ apoproteins. J. Biol. Chem. 255:8303-8307.

6. Shelburne, F., J. Hanks, W. Meyers, and S. Quarfordt. 1980. Effect of apoproteins on hepatic uptake of triglyceride emulsions in the rat. J. Clin. Invest. 65:652-658.

7. Hui, D. Y., T. L. Innerarity, and R. W. Mahley. 1981. Lipoprotein binding to canine hepatic membranes. Metabolically distinct apo E and apo B, E receptors. J. Biol. Chem. 256:5646-5655.

8. Mahley, R. W., D. Y. Hui, T. L. Innerarity, and K. H. Weisgraber. 1981. Two independent lipoprotein receptors on hepatic membranes of dog, swine and man. J. Clin. Invest. 68:1197-1206.

9. Utermann, G., M. Hees, and A. Steinmetz. 1977. Polymorphism of apolipoprotein $E$ and occurrence of dysbetalipoproteinemia in man. Nature (Lond.). 269:604-607.

10. Zannis, V. I., and J. L. Breslow. 1981. Human very low density lipoprotein apolipoprotein $\mathrm{E}$ isoprotein polymorphism is explained by genetic variation and post-translational modification. Biochemistry. 20:1033-1041.

11. Zannis, V. I., P. W. Just, and J. L. Breslow. 1981. Human apolipoprotein $\mathrm{E}$ isoprotein subclasses are genetically determined. Am. J. Hum. Genet. 33:11-34.

12. Utermann, G., I. Kindermann, H. Kaffarnik, and A. Steinmetz. 1984. Apolipoprotein E phenotypes and hyperlipidemia. Hum. Genet. 65:232-236.

13. Assmann, G., G. Schmitz, H. J. Menzel, and H. Schulte. 1984. Apolipoprotein E polymorphism and hyperlipidemia. Clin. Chem. 30:641-643.

14. Wardell, M. R., P. A. Suckling, and E. D. Janus. 1982. Genetic variation in human apolipoprotein E. J. Lipid Res. 23:1174-1182.

15. Cumming, A. M., and F. W. Robertson. 1984. Polymorphism at the apoprotein-E locus in relation to risk of coronary disease. Clin. Genet. 25:310-313.

16. Zannis, V. I., J. L. Breslow, G. Utermann, R. W. Mahley, K. H. Weisgraber, R. J. Havel, J. L. Goldstein, M. S. Brown, G. Schonfeld, W. R. Hazzard, and C. B. Blum. 1982. Proposed nomenclature of apo E isoprotein genotypes and phenotypes. J. Lipid Res. 23:911-914.

17. Utermann, G., K. H. Vogelberg, A. Steinmetz, W. Schoenborn, N. Pruin, M. Jaeschke, and M. Hees. 1979. Polymorphism of apolipoprotein E. II. Genetics of hyperlipoproteinemia type III. Clin. Genet. 15:37-62.

18. Fainaru, M., R. W. Mahley, R. L. Hamilton, and T. L. Innerarity. 1982. Structural and metabolic heterogeneity of B-very low density lipoproteins from cholesterol-fed dogs and from humans with type III hyperlipoproteinemia. J. Lipid Res. 23:702-714.

19. Weisgraber, K. H., T. L. Innerarity, and R. W. Mahley. 1982. Abnormal lipoprotein receptor-binding activity of the human $\mathrm{E}$ apoprotein due to cysteine-arginine interchange at a single site. J. Biol. Chem. 257:2818-2821.

20. Mahley, R. W., and T. L. Innerarity. 1983. Lipoprotein receptors and cholesterol homeostasis. Biochim. Biophys. Acta. 737:197222.

21. Menzel, H. J., R. G. Kladetzky, and G. Assmann. 1983. Apolipoprotein E-polymorphism and coronary artery disease. Arteriosclerosis. 3:310-315.

22. Utermann, G., N. Pruin, and A. Steinmetz. 1979. Polymorphism of apolipoprotein E. III. Effect of a single polymorphic gene locus on plasma lipid levels in man. Clin. Genet. 15:63-72.

23. Forbes, W. R., and A. M. Cumming. 1985. Effects of apoprotein E polymorphism on serum lipoprotein concentration. Arteriosclerosis. 5:283-292.

24. Ehnholm, C., M. Lukka, T. Kuusi, E. Nikkila, and G. Utermann. 1986. Apolipoprotein E polymorphism in the Finnish popula- tion: gene frequencies and relation to lipoprotein concentrations. $J$. Lipid Res. 27:227-235.

25: Castelli, W. P., J. T. Doyle, T. Gordon, C. G. Hames, M. C. Hjortland, S. B. Hulley, et al. 1977. HDL cholesterol and other lipids in coronary heart disease. The cooperative lipoprotein phenotyping study. Circulation. 56:767-772.

26. Wilson, P. W., R. J. Garrison, W. P. Castelli, M. Feinleib, P. M. McNamara, and W. B. Kannel. 1980. Prevalence of coronary heart disease in the Framingham offspring study. Role of lipoprotein cholesterols. Am. J. Cardiol. 46:649-654.

27. Hazzard, W. R., and E. L. Bierman. 1976. Delayed clearance of chylomicron remnants following vitamin A-containing oral fat load in broad-B disease (type III hyperlipoproteinemia). Metab. Clin. Exp. 25:777-801.

28. Wilson, D. E., I. Chan, and M. Ball. 1983. Plasma lipoprotein retinoides after vitamin A feeding in normal man. Minimal appearance of retinyl esters among low-density lipoproteins. Metab. Clin. Exp. 32:514-517.

29. Berr, F., and F. Kern, Jr. 1984. Plasma clearance of chylomicrons labelled with retinyl palmitate in healthy human subjects. $J$. Lipid Res. 25:805-812.

30. Wilson, D. E., I. Chan, K. N. Buch, and S. C. Herton. 1985. Postchallenge plasma lipoprotein retinoids: chylomicron remnants in endogenous hypertriglyceridemia. Metab. Clin. Exp. 34:551-558.

31. Berr, F., R. H. Eckel, and F. Kern. 1985. Plasma decay of chylomicron remnants is not affected by heparin-stimulated plasma lipolytic activity in normal fasting man. J. Lipid Res. 26:852-859.

32. Berr, F., R. H. Eckel, and F. Kern. 1986. Contraceptive steroids increase hepatic uptake of chylomicron remnants in healthy young women. J. Lipid Res. 27:645-651.

33. Cortner, J. A., P. M. Coates, N. A. Le, D. D. Cryer, M. C. Ragni, A. Faulkner, and T. Langer. 1987. Kinetics of chylomicron remnant clearance in normal and hyperlipoproteinemic subjects. $J$. Lipid Res. 28:195-206.

34. Weintraub, M. S., S. Eisenberg, and J. L. Breslow. 1987. Different patterns of postprandial metabolism in normals, and type IIa, type III and type IV hyperlipoproteinemics. Effects of treatment with cholestyramine and gemfibrozil. J. Clin. Invest. 79:1110-1119.

35. Grundy, S. M., and H. Y. I. Mok. 1976. Chylomicron clearance in normal and hyperlipidemic man. Metab. Clin. Exp. 25:1225-1239.

36. Dole, V. P., and J. I. Hamlin. 1962. Particulate fat in lymph and blood. Physiol. Rev. 42:674-701.

37. Lindgren, F. T., L. C. Jensen, and F. T. Hatch. 1972. The isolation and quantitative analysis of serum lipoproteins. In Blood Lipids and Lipoproteins: Quantitation, Composition and Metabolism. G. S. Nelson, editor. Wiley Interscience, New York. 181-274.

38. Blomhoff, R., M. Rasmussen, A. Nielsen, K. R. Norum, T. Berg, W. S. Blaner, M. Kato, J. R. Mertz, D. S. Goodman, U. Erikson, and A. Peterson. 1985. Hepatic retinol metabolism. J. Biol. Chem. 260:13560-13565.

39. DeRuyten, M. G. M., and A. P. Deleenheer. 1978. Simultaneous determination of retinol and retinyl esters in serum or plasma by reversed-phase high performance liquid chromatography. Clin. Chem. 24:1920-1923.

40. Warnick, G. R., J. Benderson, and J. J. Albers. 1982. Dextran sulfate- $\mathrm{Mg}^{2+}$ precipitation procedure for quantitation of high density lipoprotein cholesterol. Clin. Chem. 28:1379-1388.

41. Krauss, R. M., R. I. Levy, and D. S. Fredrickson. 1974. Selective measurement of two lipase activities in post heparin plasma from normal subjects and patients with hyperlipoproteinemia. J. Clin. In vest. $54: 1107-1124$.

42. Rall, S. C., K. H. Weisgraber, and R. W. Mahley. 1981. Human apolipoprotein E. The complete amino acid sequence. J. Biol. Chem. 257:4171-4178.

43. Innerarity, T. L., E. J. Friedlander, S. C. Rall, Jr., K. H. Weis- 
graber, and R. W. Mahley. 1983. The receptor-binding domain of human apolipoprotein E. Binding of apolipoprotein fragments. J. Biol. Chem. 258:12341-12347.

44. Weisgraber, K. H., T. L. Innerarity, K. J. Harder, R. W. Mahley, R. W. Milne, Y. L. Marcel, and J. T. Sparrow. 1983. The receptor-binding domain of human apolipoprotein E. Monoclonal antibody inhibition of binding. J. Biol. Chem. 258:12348-12354.

45. Innerarity, T. L., K. H. Weisgraber, K. S. Arnold, S. C. Rall, Jr., and R. W. Mahley. 1984. Normalization of receptor binding of apolipoprotein E2. Evidence for modulation of the binding site conformation. J. Biol. Chem. 259:7261-7267.

46. Mahley, R. W., and B. Angelin. 1984. Type III hyperlipoproteinemia recent insights into the genetic defect of familial dysbetalipoproteinemia. Adv. Intern. Med. 29:385-411.

47. Breslow, J. L., and V. I. Zannis VI. 1986. Genetic variation in apolipoprotein E and type III hyperlipoproteinemia. In Arteriosclerosis Reviews. A. M. Gotto and T. Paoletti, editors. Raven Press, New York. Vol. 14. 119-141.

48. Schmitz, G., G. Assmann, J. Augustin, A. Kirkes-Kersting, B. Brennhausen, and C. Karoff. 1985. Characterization of very low den- sity lipoproteins of normo- and hyperlipidemic apolipoprotein E-2 homozygotes. J. Lipid Res. 26:316-326.

49. Imaizumi, K., M. Fainaru, and R. J. Havel. 1978. Composition of proteins of mesenteric lymph chylomicrons in the rat and alterations produced upon exposure of chylomicrons to blood serum and serum proteins. J. Lipid Res. 19:712-722.

50. Green, P. H. R., R. M. Glickman, C. D. Saudek, C. B. Blum, and A. R. Tall. 1979. Human intestinal lipoproteins: studies in chyluric subjects. J. Clin. Invest. 64:233-242.

51. Blum, C. B. 1982. Dynamics of apolipoprotein E metabolism in humans. J. Lipid Res. 23:1308-1316.

52. Weisgraber, K. H., and R. W. Mahley. 1978. Apoprotein (EAII) complex of human plasma lipoproteins. I. Characterization of this mixed disulfide and its identification in a high density lipoprotein subfraction. J. Biol. Chem. 253:6281-6288.

53. Gregg, R. E., L. A. Zech, E. J. Schaefer, D. Stark, D. Wilson, and B. Brewer, Jr. 1986. Abnormal in vivo metabolism of apolipoprotein E4 in humans. J. Clin. Invest. 78:815-821.

54. Sing, C. F., and J. Davignon. 1985. Role of apolipoprotein E genetic polymorphism in determining normal plasma lipid and lipoprotein variation. Am. J. Hum. Genet. 37:268-285. 